\title{
Synthesis, transformation, catalysis and gas sorption investigations on the bismuth metal-organic framework CAU-17
}

\author{
Milan Köppen, ${ }^{[a]}$ Amarajothi Dhakshinamoorthy, ${ }^{[a, b]}$ A. Ken Inge, ${ }^{[a, c]}$ Ocean Cheung, ${ }^{[d]}$ Jonas \\ Ångström, ${ }^{[\mathrm{c}]}$ Peter Mayer ${ }^{[\mathrm{e}]}$ and Norbert Stock ${ }^{*[a]}$
}

\begin{abstract}
Very few microporous bismuth metal-organic frameworks have been discovered to date, and of these no detailed experimental characterization of the synthesis and properties have been reported until now for the only one which can be prepared from inexpensive starting materials: $\mathrm{CAU}-17$ [Bi(BTC) $\left.\left(\mathrm{H}_{2} \mathrm{O}\right)\right]$, with $\mathrm{H}_{3} \mathrm{BTC}=$ trimesic acid In situ X-ray powder diffraction during solvothermal synthesis of $\mathrm{CAU}$ 17 revealed that it crystallizes rapidly within 2 minutes, and if the reaction is not stopped the MOF transforms into a nonporous dense purely inorganic material within one hour, revealing that CAU-17 is a crystalline intermediate phase. Synthesis scale-up employing more concentrated reaction mixtures resulted in another $\mathrm{Bi}$ trimesate of composition $\left[\mathrm{Bi}(\mathrm{HBTC})\left(\mathrm{NO}_{3}\right)(\mathrm{MeOH})\right] \cdot \mathrm{MeOH}$, which structurally decomposes upon storage under ambient conditions. Sorption experiments showed that $\mathrm{CAU}-17$ is microporous with a BET surface area of $530 \mathrm{~m}^{2} / \mathrm{g}$. As a potential greenhouse gas sorbent, CAU-17 showed high $\mathrm{SF}_{6} / \mathrm{N}_{2}$ and $\mathrm{CO}_{2} / \mathrm{N}_{2}$ selectivity $>31$ and 29 , respectively. Furthermore, the catalytic activity of CAU-17 was studied in the regioselective ring-opening of styrene oxide by methanol to obtain 2 methoxy-2-phenylethanol, thus demonstrating the existence of coordinatively unsaturated sites in the crystal structure of CAU-17.
\end{abstract}

\section{Introduction}

Metal-organic frameworks ${ }^{[1-6]}$ (MOFs) are a flourishing class of porous materials built of metal cations bridged by organic linker molecules, and have potential applications in gas storage,$^{[7]}$ gas

[a] M.Sc. M. Köppen, Prof. Dr. N. Stock Institut für Anorganische Chemie Christian-Albrechts-Universität zu Kiel Max-Eyth Str. 2, 24118 Kiel (Germany) E-mail: stock@ac.uni-kiel.de

[b] Prof. Dr. A. Dhakshinamoorthy School of Chemistry Madurai Kamaraj University Madurai-625 021, Tamil Nadu (India)

[c] Dr. A. Ken Inge, Dr. J. Ångström Department of Materials and Environmental Chemistry Stockholm University, Stockholm SE-106 91 (Sweden)

[d] Dr. O. Cheung

Division for Nanotechnology and Functional Materials, Department of Engineering Sciences

Uppsala University, Uppsala SE-751 21 (Sweden)

[e] Dr. Peter Mayer

Ludwig-Maximilians-Universität München, Department Chemie Butenandtstr. 5-13, Haus D, 81377 München (Germany)

Supporting information (SI) for this article is given via a link at the end of the document. The crystallographic information for $\mathbf{3}$ is available in the Cambridge Structural Database (CSD) as CCDC 1579911. separation, ${ }^{[8]}$ heterogeneous catalysis ${ }^{[9]}$ and medicine. ${ }^{[10]}$ The use of bismuth cations in the formation of MOFs is of interest for their unusual properties for a heavy metal. Despite being the heaviest quasi-stable element $\left(\mathrm{t}_{1 / 2}\left({ }^{209} \mathrm{Bi}\right)=1.9 \cdot 10^{19} \mathrm{a}\right),{ }^{[11]}$ bismuth and its compounds are generally nontoxic and several are even used as metallodrugs to treat wounds and gastrointestinal disorders. ${ }^{[12-16]}$ Although some MOFs consisting of lighter metal cations have been predesigned and successfully synthesized through prior knowledge of common inorganic building units and concepts of reticular chemistry, ${ }^{[17]}$ the structural behavior of $\mathrm{Bi}^{3+}$ ions in solvothermal reactions of MOFs remains highly unpredictable, and most bismuth MOFs have very unique inorganic building units that differ from structure to structure. Also, the large ionic radius of $\mathrm{Bi}^{3+}$ ions $\left(r\left(\mathrm{Bi}^{3+}\right)=1.31 \AA\right.$, $\left.\mathrm{CN}=8\right)$ leads to highly complex and irregular coordination geometries around the $\mathrm{Bi}^{3+}$ cations, which are often influenced by the $6 s^{2}$ lone pair of electrons. ${ }^{[18]}$ Characterization of bismuth oxido clusters forming as metastable reaction products is a big challenge, as demonstrated in literature. ${ }^{[19]}$

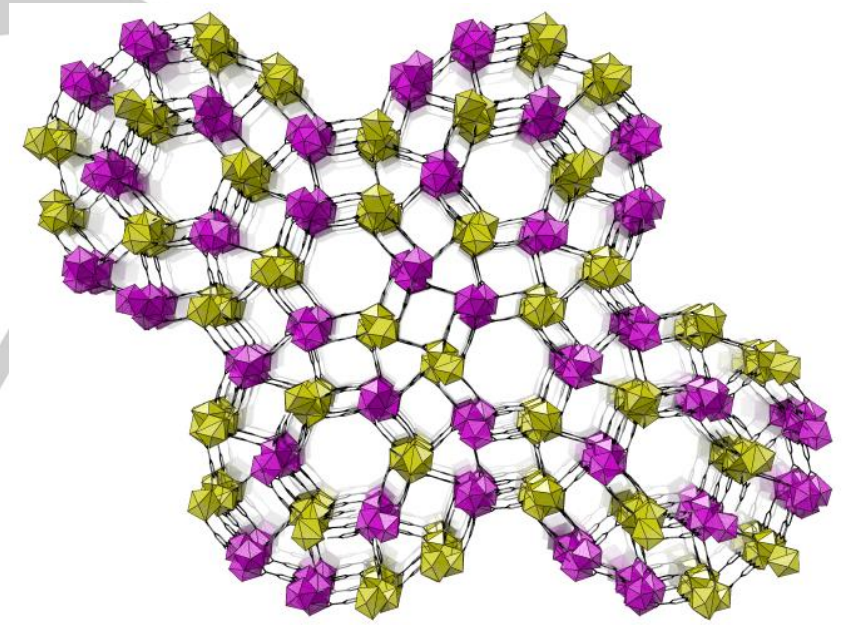

Figure 1. Crystal structure of $\mathrm{CAU}-17$ (view along [001]). Bi-O-helices are shown in yellow (left handed) and purple (right handed).

However, the synthesis of microporous bismuth-based MOFs still remains a challenge today. Only four permanently microporous MOFs (i.e. type I isotherms for $\mathrm{N}_{2}$ ) have been successfully synthesized using $\mathrm{Bi}^{3+}$ cations, to the best of our knowledge, including CAU-7, ${ }^{[20]}$ NOTT-220, ${ }^{[21]} \mathrm{CAU}-17^{[22]}$ and CAU-35. ${ }^{[23]}$ All of these MOFs have only been discovered within the past five years, and relatively few detailed analyses of their properties and their potential applications have been reported. CAU-7 has been described as a mild heterogeneous Lewis acid catalyst as demonstrated for the hydroxymethylation of 2-methylfuran, ${ }^{[20]}$ and high gravimetric uptake of $\mathrm{CO}_{2}$ and $\mathrm{CH}_{4}$ was reported for NOTT- 
$220 .{ }^{[21]}$ Of these four microporous bismuth MOFs, CAU-17 is the only one that is synthesized using an inexpensive reagent for the organic linker: trimesic acid. We recently reported the crystal structure of CAU-17 (1, $\left[\mathrm{Bi}(\mathrm{BTC})\left(\mathrm{H}_{2} \mathrm{O}\right)\right]$, where $\mathrm{BTC}^{3-}=1,3,5-$ benzenetricarboxylate or trimesate), although without details of its synthesis, transformations, properties, and potential applications. ${ }^{[22]}$ The crystal structure is built of left- and righthanded helices of edge-sharing $\mathrm{BiO}_{9}$-polyhedra that are linked by $\mathrm{BTC}^{3-}$ ions to form a framework with hexagonal, rectangular and triangular channels with pore diameters of 9.6, 3.6 and $3.4 \AA$, respectively, as obtained by considering the van der Waals radii of the pore wall atoms (Fig. 1). ${ }^{[22]}$ Every $\mathrm{Bi}^{3+}$ ion is coordinated by one terminal $\mathrm{H}_{2} \mathrm{O}$ molecule, which can be removed reversibly (see $\mathrm{H}_{2} \mathrm{O}$ sorption in supporting information (SI)). Regarding its topology, CAU-17 has by far the most complex underlying net among all observed MOF structures to date with 54 unique nodes connected by 135 edges. As CAU-17 is currently the only bismuth MOF that can be synthesized from inexpensive reagents and is one of the more intricate MOF structures known to date, detailed studies on its synthesis, stability and properties are certainly warranted.

Researchers have been striving to improve their understanding of the synthesis mechanisms of MOFs in order to achieve better control over their particle size, shape, and other physical and chemical properties and also to discover novel short-lived intermediate phases. ${ }^{[24]}$ Since solvothermal reactions are often performed with long reaction times (typically on the order of days or weeks), short-lived crystalline intermediates can easily be overlooked. Intermediates can be more interesting than the products they eventually transform into with prolonged reaction times, since later products tend to form more thermodynamically stable dense crystal structures. In situ powder X-ray diffraction (PXRD) has been an invaluable tool for understanding such crystallization processes. ${ }^{[25-27]}$ In an investigation of the synthesis mechanisms of bismuth trimesates hydrothermally synthesized in water in situ PXRD revealed rapid formation of the first crystalline product, followed by sequential transformations into a second and third crystalline phase after extended heating time. ${ }^{[28]}$ The evolution of the materials with heating time was elucidated by quenching the reaction to isolate the three individual phases for crystal structure determination. ${ }^{[28]}$ In total, six crystalline bismuth trimesate structures have been reported thus far, and the large number of crystal structures that can be synthesized from the same combination of $\mathrm{Bi}^{3+}$ and linker is attributed to the flexible coordination environment of $\mathrm{Bi}^{3+}$ ions. However, apart from CAU17, which is synthesized in methanol, the remaining five crystalline phases are dense nonporous materials. ${ }^{\text {28-30] }}$

MOFs are widely studied heterogeneous catalysts due to their unique properties, high surface areas and the availability of different active sites. ${ }^{[31-34]}$ Among the various positions of active sites such as in the linkers or in the empty spaces of MOFs, ${ }^{[35]}$ one of the frequently used active sites in MOFs are the metal nodes as Lewis acid sites. ${ }^{[36-39]}$ Ring opening of epoxides is considered as a model reaction to probe the catalytic activity of different solid materials with such active sites. ${ }^{[35,40-46]}$ Obviously, these solids are expected to be beneficial in comparison to their corresponding homogeneous counterpart due to the ability to recover and reuse the catalyst in consecutive cycles.

Storage and separation of gases is another important property of MOFs which has been in the focus of many investigations. Thus Zhou and coworkers very recently performed grand canonical Monte Carlo simulations and dispersion-corrected density functional theory to model the sorption of $\mathrm{CH}_{4}$ and $\mathrm{H}_{2}$ by $\mathrm{CAU}-17$ which suggest the material has high $\mathrm{CH}_{4} / \mathrm{H}_{2}$ selectivity compared to several classic MOFs. ${ }^{[47]}$ Due to the pore diameter of the hexagonal pores of CAU-17 (9.6 from the crystal structure) this MOF could be of particular interest for adsorption and separation of the greenhouse gas $\mathrm{SF}_{6}$, which is considered as the most potent greenhouse gas according to an investigation by the Intergovernmental Panel on Climate Change. ${ }^{[48]}$ Other microporous materials with similar pore diameters, such as zeolite $\mathrm{Y}(10 \AA),{ }^{[49]}$ MOF-74 $(11 \AA)^{[50]}$ and porous organic cages ${ }^{[51]}$ have been shown to be suitable for the separation of $\mathrm{SF}_{6}$ from $\mathrm{N}_{2}$.

Herein we present the results of our systematic study on the synthesis and transformation of CAU- 17 by in situ PXRD, thermal and chemical stability, and its application in heterogeneous catalysis and gas separation. In this work we present for the first time in situ PXRD studies, utilizing a custom-built reactor, on the formation and transformation of $\mathrm{CAU}-17$ revealing that the material is a crystalline intermediate.

\section{Results and Discussion}

\section{Synthesis and transformation of CAU-17}

The synthesis of CAU-17 was systematically studied to learn more about the crystallization process and to optimize the synthesis, i.e. to improve the yield. The synthesis was always performed in glass vials, which were either placed in a pre-heated aluminium block or heated by microwave radiation and stirred during the reaction. The vials were utilized with a volume of 2.5 $\mathrm{mL}$ or $20 \mathrm{~mL}$ solvent respectively. The in situ PXRD studies were carried out in the custom-made SynRAC (synchrotron-based reaction cell for the analysis of chemical reactions) set-up. ${ }^{[52]}$ It allows the investigation of solvothermal syntheses in glass vials, which are typically used in research and which have been used in reactions employing the aforementioned custom-made aluminium block. These vials can be heated to the target temperature within only a few minutes (Fig. S3-S9). The set-up can be penetrated by synchrotron X-rays, allowing in situ PXRD data to be collected during formation and transformation of crystalline products without disturbing the solvothermal reaction. The in situ PXRD studies of the crystallization of CAU-17 revealed that it already forms during the heat-up process even before the reaction mixture reaches the target temperature (Fig. 2). After a short reaction time, porous $\mathrm{CAU}-17$ transforms into an unknown purely inorganic dense phase of composition $\mathrm{Bi}_{2} \mathrm{O}(\mathrm{OH})_{3}\left(\mathrm{NO}_{3}\right) \cdot \mathrm{xH}_{2} \mathrm{O}$ (2) (Fig. S11), which could not be structurally characterized due to poor crystallinity. Increasing the reaction temperature also increases the rate of transformation. Bragg reflections of 2 appear after 31 $\min \left(120^{\circ} \mathrm{C}\right), 18 \min \left(130^{\circ} \mathrm{C}\right)$ and $11 \min \left(140^{\circ} \mathrm{C}\right)$ of reaction time (Fig. S2). These observations are consistent with the fact that products with denser (non-porous) crystal structures are generally 
thermodynamically more stable and tend to form after longer reaction times.

The synthesis of CAU-17 is generally sensitive to changes of the reaction conditions. Especially at lower temperatures $\left(<120^{\circ} \mathrm{C}\right)$, the reaction mixture tends to form unknown impurities at short reaction times. To synthesize phase pure CAU-17, the synthesis conditions were optimized to a reaction time of $20 \mathrm{~min}$ and a temperature of $120{ }^{\circ} \mathrm{C}$. Since in situ PXRD revealed that the crystallization of CAU-17 occurs spontaneously during the initial heat-up process, a kinetic study of the crystallization process was not possible.

Structural characterization of $\mathbf{2}$ was not successful. Continuous rotation electron diffraction ${ }^{[53]}$ was employed to determine the structure of $\mathbf{2}$, or at least the lattice parameters, but due to diffuse scattering along the $\mathrm{c}^{*}$ axis (Fig. S10) this could not be accomplished despite numerous attempts. However, the two wellordered axes indicate that the lattice parameters are approximately: $a=10 \AA, b=10 \AA, c=\mathrm{X}, \alpha=90^{\circ}, \beta=90^{\circ}, \gamma=$ $120^{\circ}$ ( $X$ could not be established due to diffuse scattering). Elemental and TG analysis revealed the formation of a purely inorganic compound with the composition $\mathrm{Bi}_{2} \mathrm{O}(\mathrm{OH})_{3}\left(\mathrm{NO}_{3}\right) \cdot \times \mathrm{H}_{2} \mathrm{O}$ (Tab. S1 and Fig. S13). Thus, this transformation can only take place in a nitrate ion containing medium, such as the reaction mixture.

During the synthesis optimization of CAU-17 a new crystalline phase, $\left[\mathrm{Bi}(\mathrm{HBTC})\left(\mathrm{NO}_{3}\right)(\mathrm{MeOH})\right] \cdot \mathrm{MeOH}$ (3), was discovered throughout the synthesis scale up, when the concentration of

$120^{\circ} \mathrm{C}$
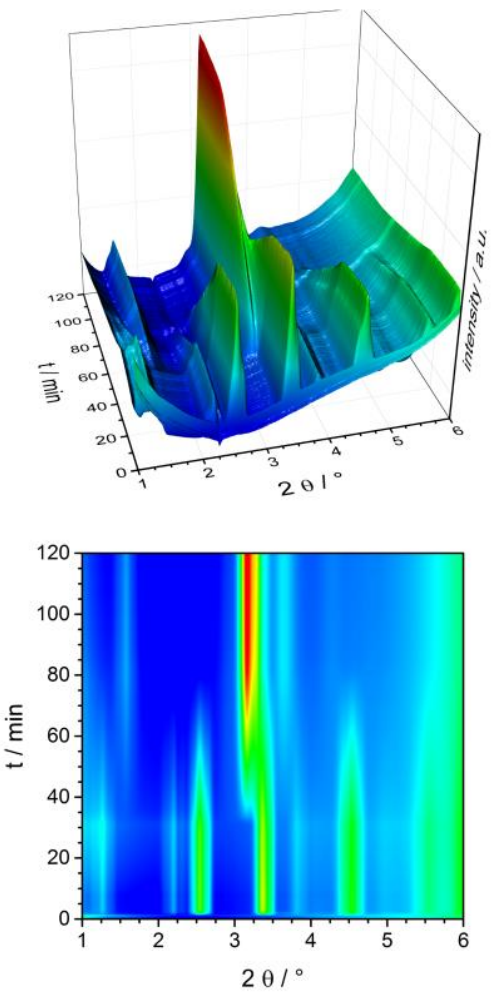

$130{ }^{\circ} \mathrm{C}$
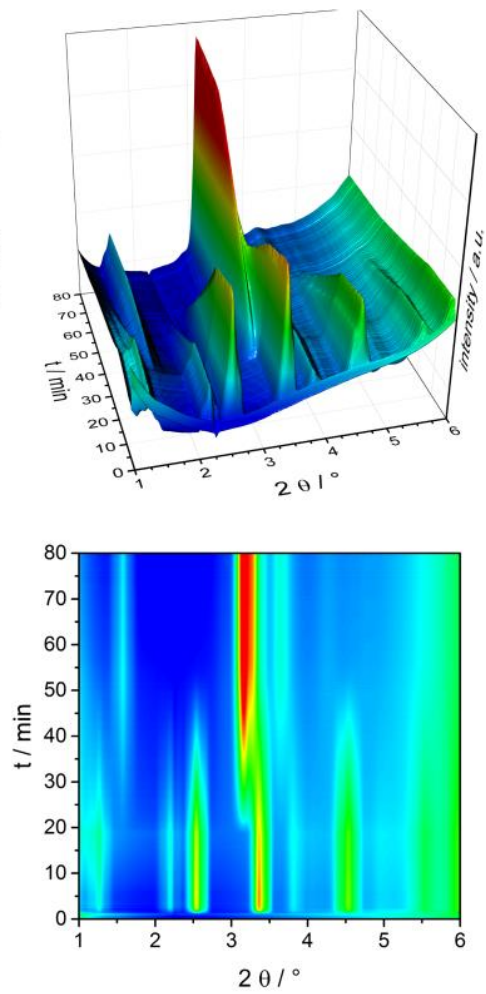

starting materials was increased (crystallographic and refinement details are provided in the SI). The open-framework structure of $\mathbf{3}$ is built of corner sharing $\mathrm{BiO}_{9}$ polyhedra that are interconnected by $\mathrm{NO}_{3}{ }^{-}$ions to form chains along the a-axis. Three chains are connected by a $\mathrm{HBTC}^{2-}$ ion resulting in a one-dimensional channel system along the a-axis. The $-\mathrm{COOH}$ group only coordinates with one oxygen atom to the $\mathrm{Bi}^{3+}$ ion, while in contrast the $-\mathrm{COO}^{-}$groups coordinate as bidentate ligands. Every $\mathrm{Bi}^{3+}$ ion has a terminally coordinating methanol molecule in its coordination sphere, and additionally there is one methanol molecule per formula unit in the pores as a guest (Fig. 3 and Fig. S33-S35). Upon storage under ambient conditions the compound rapidly loses its crystallinity due to the removal of methanol.
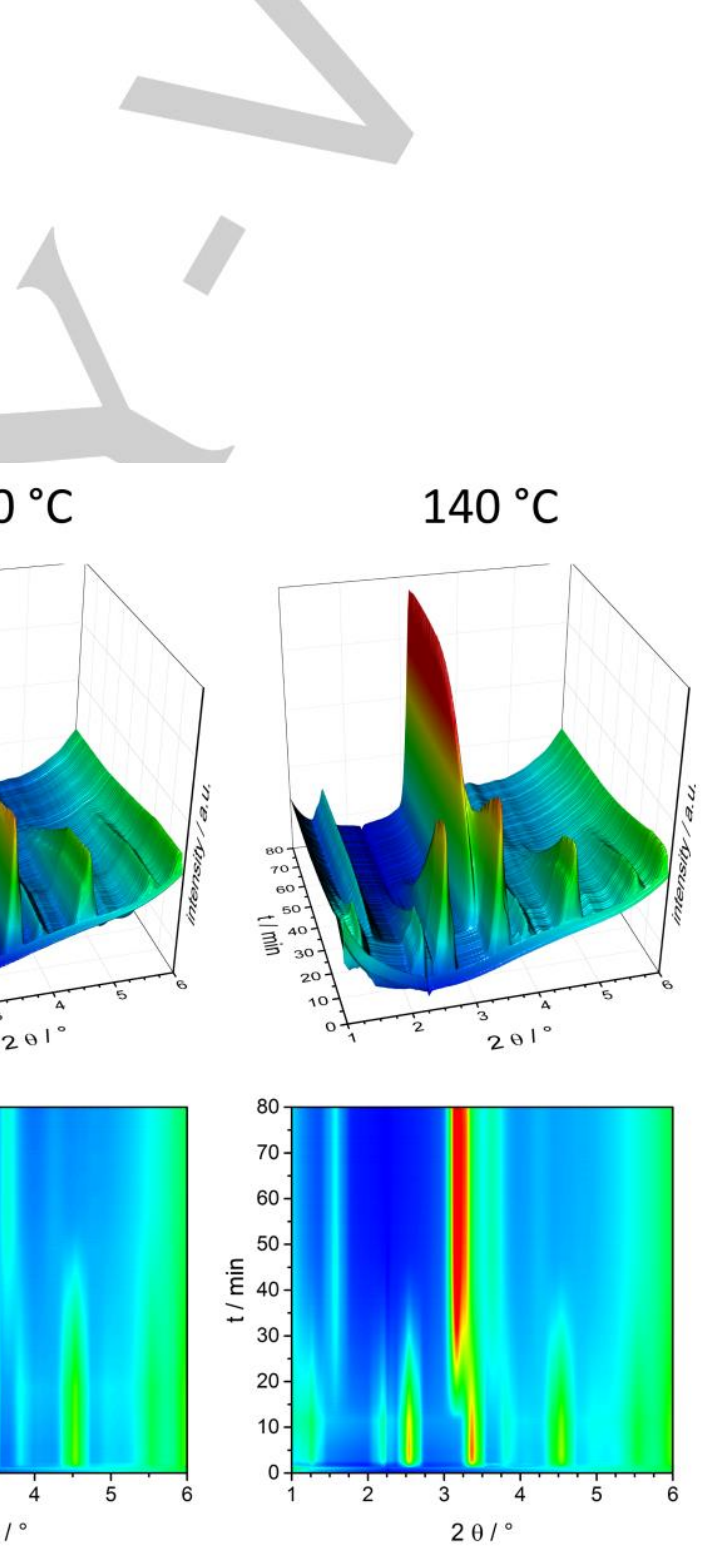

Figure 2. In situ PXRD datasets collected during the reaction of $\mathrm{Bi}^{3+}$ with $\mathrm{H}_{3} \mathrm{BTC}$ in methanol employing synchrotron radiation at beamline P09, $\mathrm{PETRA}$ III, Hamburg, Germany $(\lambda=0.539 \AA$ ). (Top) 3D projection, (bottom) 2D projection. The conversion of CAU-17 into 2 is noticeably faster at higher temperatures. 


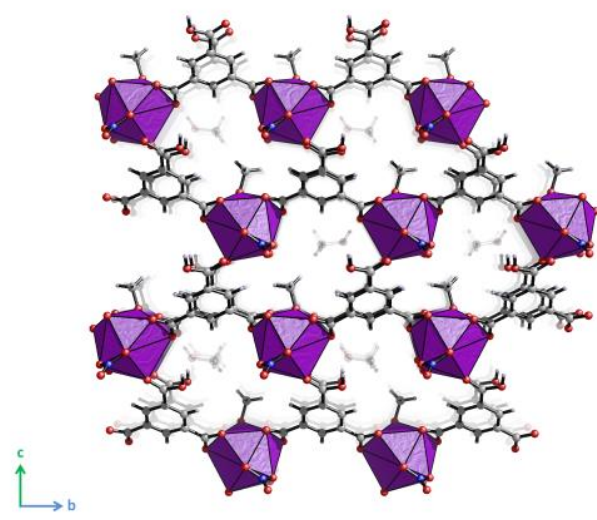

Figure 3. Crystal structure of $\left[\mathrm{Bi}(\mathrm{HBTC})\left(\mathrm{NO}_{3}\right)(\mathrm{MeOH})\right] \cdot \mathrm{MeOH}$ (3). Bismuth cations are represented as purple polyhedra. Carbon, nitrogen and hydrogen atoms are colored grey, blue and pink respectively. Guest molecules $(\mathrm{MeOH})$ in the pores are translucent.

\section{Thermal and chemical stability}

Temperature-dependent PXRD performed in an open capillary revealed changes to the unit cell parameters of $\mathrm{CAU}-17$ at elevated temperatures, which could be recognized by small shifts of the reflections (Fig. 4). A sequential Le Bail fit of the PXRD patterns was performed to analyze the temperature dependency of the unit cell parameters (with error bars see, Fig. S14). The unit cell volume as well as the cell parameters $a$ and $b$ increase from room temperature up to $100^{\circ} \mathrm{C}$ while the parameter $c$ decreases, indicating a contraction of the inorganic helices. Up to ca. $120^{\circ} \mathrm{C}$, as determined by thermogravimetric (TG) measurement (Fig. S27), the coordinated $\mathrm{H}_{2} \mathrm{O}$ molecules are removed. Although the sample temperature is further increased a shrinking of all unit cell parameters and the unit cell volume up to a temperature of $\mathrm{T}=270{ }^{\circ} \mathrm{C}$ is observed. This qualifies CAU-17 for further investigations of the phenomenon negative thermal expansion (NTE), which has already been reported for other metal-organic frameworks, but a detailed investigation of this property is outside the scope of this publication. ${ }^{[54]}$ Finally, framework decomposition was observed at $\sim 370{ }^{\circ} \mathrm{C}$.

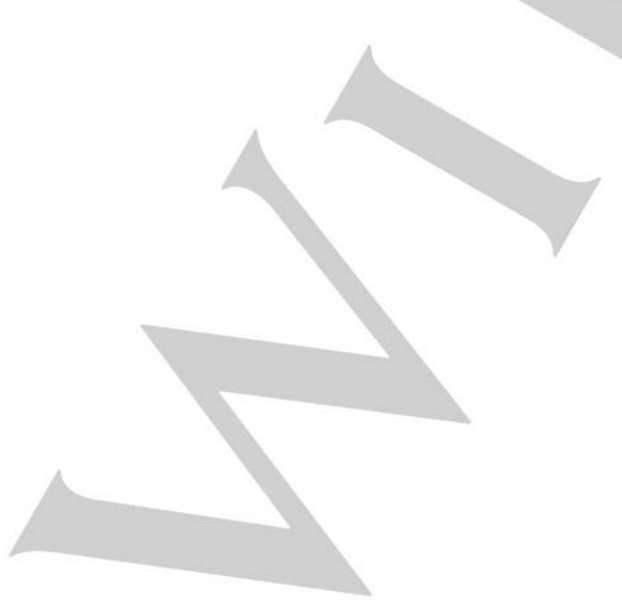

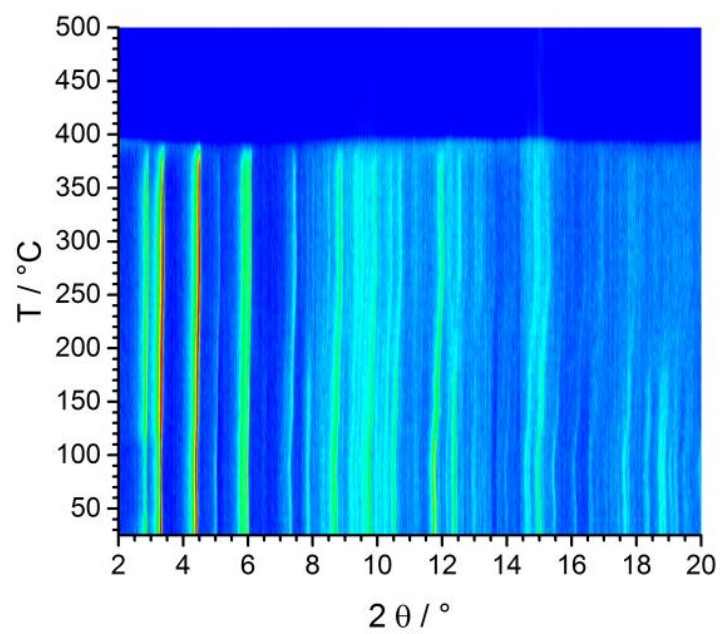

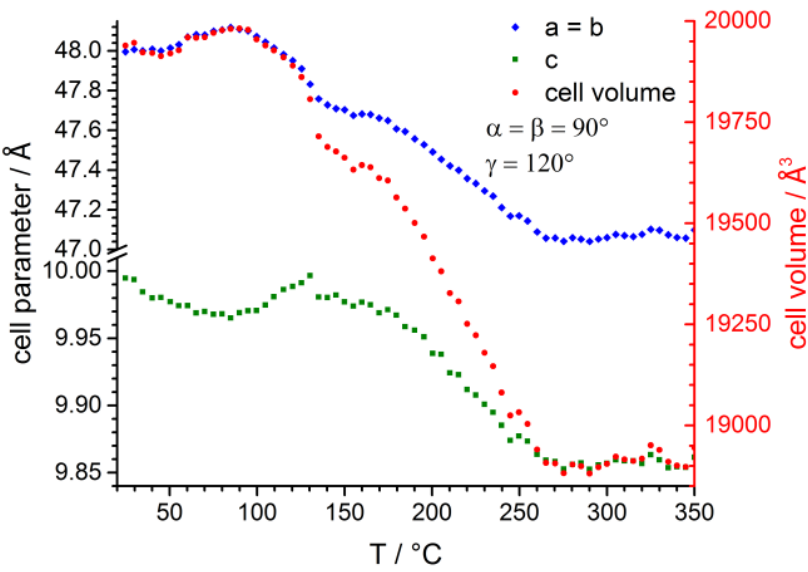

Figure 4. Temperature-dependent PXRD data (top, $\lambda=0.7093 \AA$ ) and results of a sequential Le Bail fit of the cell parameters of CAU-17 (bottom).

To investigate the chemical stability of CAU-17, $20 \mathrm{mg}$ of the MOF were each stirred in different solvents for $24 \mathrm{~h}$ at room temperature, filtered and washed with methanol. The exposure to water and aqueous $\mathrm{HCl} / \mathrm{NaOH}$ at different $\mathrm{pH}$ led to a (partial) structural transformation of CAU-17 $\left(\left[\mathrm{Bi}(\mathrm{BTC})\left(\mathrm{H}_{2} \mathrm{O}\right)\right]\right)$ into the dense pseudo-polymorph $\left[\mathrm{Bi}(\mathrm{BTC})\left(\mathrm{H}_{2} \mathrm{O}\right)\right] \cdot \mathrm{H}_{2} \mathrm{O}^{[28]}(4)$ or resulted in the full degradation of the $\mathrm{CAU}-17$ structure. However, in organic solvents, the structure was maintained in most stability tests. The PXRD patterns of these products and their analysis are given in the SI (Fig. S15-S17).

In order to attain insight into the stability of CAU-17 in water at elevated temperatures, $15 \mathrm{mg}$ of CAU-17 was stirred in $2.5 \mathrm{ml}$ $\mathrm{H}_{2} \mathrm{O}$, while simultaneously recording in situ PXRD data of the mixture. In order to accelerate the expected transformation from CAU-17 into 4, the temperature of the mixture was first set to $120^{\circ} \mathrm{C}$ and kept for $90 \mathrm{~min}$. Surprisingly, no immediate structural change was observed. Hence the temperature was stepwise increased by $10^{\circ} \mathrm{C}$ every $30 \mathrm{~min}$. Finally at $160^{\circ} \mathrm{C} / 180 \mathrm{~min}$ (Fig. 5 , right, blue dashed line) a decrease in the intensities of the 
reflections takes place and at $170{ }^{\circ} \mathrm{C}$ (Fig. 5, right, red dashed line), a sudden change in the powder pattern occurs and CAU-17 transforms to a product with low crystallinity which is different from 2 (Fig. S18). This experiment indicates that CAU-17 can be exposed to water for a rather short time, even at elevated temperatures up $150{ }^{\circ} \mathrm{C}$ without losing its crystallinity, while an exposure to aqueous solutions for $24 \mathrm{~h}$ at room temperature leads to a partial degradation of CAU-17. However, storing CAU-17 under ambient conditions does not cause degradation of the crystal structure which was proven by PXRD of a $\sim 2$ year old sample, Fig. S29).
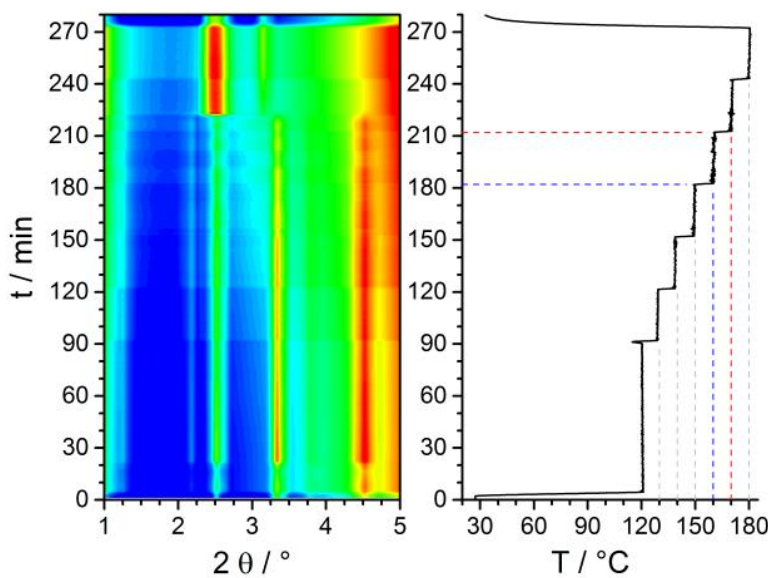

Figure 5. (Left) In situ PXRD datasets collected during the stirring of CAU-17 in water at elevated temperatures $(\lambda=0.539 \AA)$. (Right) Reaction time and temperature corresponding to the in situ PXRD data shown left.

\section{Greenhouse gas separation and adsorption}

The sorption properties of CAU-17 were also investigated in detail. The Langmuir ( $\mathrm{S}_{\text {Langmuir }}$ ) and BET $\left(\mathrm{S}_{\mathrm{BET}}\right)$ surface areas were determined by $\mathrm{N}_{2}$ sorption as $650 \mathrm{~m}^{2} / \mathrm{g}$ and $530 \mathrm{~m}^{2} / \mathrm{g}$, respectively. The total micropore volume was $0.24 \mathrm{~cm}^{3} / \mathrm{g}$, calculated using the adsorption point at $\mathrm{p} / \mathrm{p}_{0}=0.98$.

In order to examine the performance of CAU-17 as an adsorbent, sorption experiments with $\mathrm{N}_{2}, \mathrm{SF}_{6}$, as well as $\mathrm{CO}_{2}$ were performed at different temperatures $\left(0-55^{\circ} \mathrm{C}\right)$ between 0 and 1 bar (Fig. S21) The $\mathrm{CO}_{2}$ and $\mathrm{SF}_{6}$ uptakes were significantly higher than the $\mathrm{N}_{2}$ uptake at all tested temperatures $\left(0,20,40,55^{\circ} \mathrm{C}\right)$. The uptake of $\mathrm{CO}_{2}$ at $0^{\circ} \mathrm{C}, 1$ bar reached $3.36 \mathrm{mmol} / \mathrm{g}$. Under the same conditions, the $\mathrm{SF}_{6}$ and the $\mathrm{N}_{2}$ uptakes were $1.61 \mathrm{mmol} / \mathrm{g}$ and $0.36 \mathrm{mmol} / \mathrm{g}$, respectively (Fig. 6). The performance of CAU-17 to separate gas mixtures was estimated using the ideal adsorbed solution theory (IAST). In the case of $\mathrm{CO}_{2} / \mathrm{N}_{2}$ mixtures, a temperature dependency was observed. The selectivity dropped from $\sim 29$ at $0{ }^{\circ} \mathrm{C}$ to 15 at $55^{\circ} \mathrm{C}$ (at $100 \mathrm{kPa}$ ). Simulations performed by Zhou et al. on CAU-17 suggested a $\mathrm{CO}_{2} / \mathrm{N}_{2}$ selectivity (at $25^{\circ} \mathrm{C} 1$ bar) lower than that calculated here using IAST based on our experimental data across the entire tested temperature range. ${ }^{[4]]}$ The selectivity for $\mathrm{SF}_{6} / \mathrm{N}_{2}$ mixtures was higher in general, and fairly constant $(\sim 31)$ at all tested temperatures. The high selectivity was expected due to the diameter of the hexagonal pores, i.e. 9.6 and $9.3 \AA$ as determined from the crystal structure and DFT calculations using the $\mathrm{N}_{2}$ adsorption isotherms, respectively. The $\mathrm{SF}_{6} / \mathrm{N}_{2}$ selectivity and total uptake values of $\sim 31$ and $1.61 \mathrm{mmol} / \mathrm{g}$ for CAU-17, respectively, are not quite as high as reported for the benchmark materials Zn-MOF-74 (46.1) and Co-MOF-74 (1.96 mmol/g), calculated for a $10 \% \mathrm{SF}_{6} / 90 \% \mathrm{~N}_{2}$ mixture. ${ }^{[50]} \mathrm{A}$ detailed analysis of all sorption related results, including water adsorption experiments performed at $20^{\circ} \mathrm{C}$ and the calculated heat of adsorption for $\mathrm{CO}_{2}$ and $\mathrm{SF}_{6}$, can be found in the $\mathrm{SI}$.

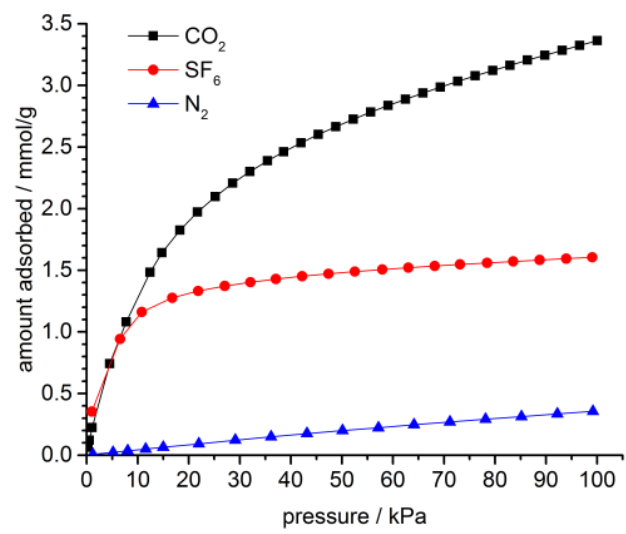

Figure 6. Adsorption isotherms of $\mathrm{CAU}-17$ with $\mathrm{CO}_{2}, \mathrm{SF}_{6}$ and $\mathrm{N}_{2}$ recorded at $0^{\circ} \mathrm{C}$

\section{Heterogeneous catalysis}

The catalytic activity of CAU-17 was investigated in the ring opening of styrene oxide to 2-methoxy-2-phenylethanol using methanol as solvent and nucleophile under mild reaction conditions (Scheme 1). Compounds $\mathbf{2}$ and $\mathbf{3}$ were not investigated due to their low crystallinity and stability, respectively.<smiles>c1ccc(C2CO2)cc1</smiles>

CAU -17 $\mathrm{MeOH}, 40{ }^{\circ} \mathrm{C}$<smiles>COC(CO)c1ccccc1</smiles>

Scheme 1. Regioselective ring opening reaction of styrene oxide catalyzed by CAU-17 in methanol.

The blank control experiment showed no product formation, thus indicating the need of a catalyst to promote this reaction. In contrast, the ring opening of styrene oxide in the presence of activated CAU-17 $\left(120^{\circ} \mathrm{C}, 3 \mathrm{~h}\right.$ under reduced pressure) resulted in complete conversion with $100 \%$ regioselectivity to 2 -methoxy2-phenylethanol. The time-conversion plot for this conversion with the formation of desired product is given in Figure 7. This behavior can be easily understood from the fact that the water molecules 
coordinating to $\mathrm{Bi}^{3+}$ ions in the framework can be removed, thus, creating free coordinatively unsaturated sites which in turn act as catalytic Lewis acid sites. In order to test this hypothesis, a control experiment was performed using the as-synthesized CAU-17 without any activation and the observed result clearly show a lower activity compared to the activated CAU-17 under identical reaction conditions. A filtration test was carried out to verify the stability of the CAU-17 catalyst. Thus, the catalyst was removed by filtration after $21 \mathrm{~h}$ and the reaction was continued. No further product is formed which infers that catalysis is truly heterogeneous. Furthermore, no noticeable changes are observed by PXRD (Fig. S30) and the activity of CAU-17 was retained in two consecutive catalytic reactions. These results clearly indicate that CAU-17 is a stable, recyclable catalyst for this reaction.

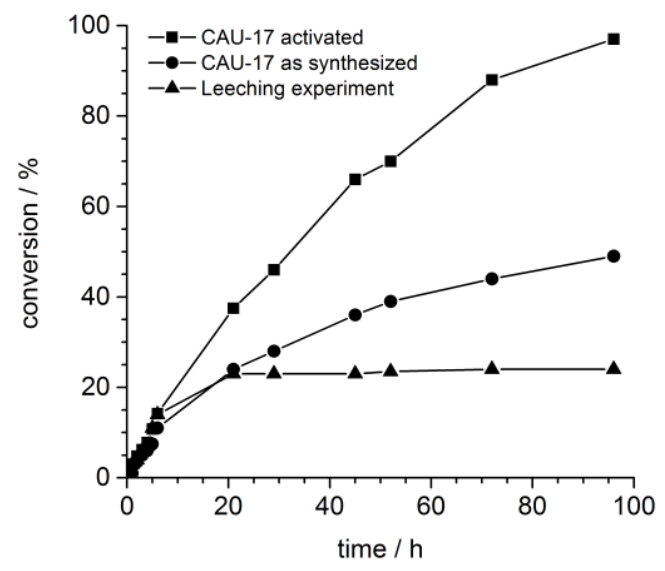

Figure 7. Time conversion plot for the ring opening of styrene oxide catalyzed by activated or as-synthesized CAU-17 and filtration test (leaching experiment). Reaction conditions: styrene oxide $(1 \mathrm{mmol})$, catalyst $(50 \mathrm{mg})$, methanol $(3 \mathrm{~mL})$, $40{ }^{\circ} \mathrm{C}$.

These encouraging results observed with $\mathrm{CAU}-17$ prompted us to compare its activity with the ones of its dense pseudo-polymorph $\left[\mathrm{Bi}(\mathrm{BTC})\left(\mathrm{H}_{2} \mathrm{O}\right)\right] \cdot \mathrm{H}_{2} \mathrm{O}^{[28]}(4)$ and the MOF CAU-7 $7^{[20]}$ under identical reaction conditions. The crystal structure of CAU-7 ([Bi(BTB)], where $\mathrm{BTB}^{3-}=1,3,5$-benzenetrisbenzoate) is built of linear chains of face sharing $\mathrm{BiO}_{9}$ polyhedra that are interconnected by $\mathrm{BTB}^{3-}$ ions to form slightly distorted hexagonal channels arranged in a honeycomb net. The observed results are presented in Figure 8. The overall conversion rate increases with time for all three catalysts. Compound $\mathbf{4}$ displayed a linear relationship between conversion rate and time, which was not observed for the other two catalysts. The initial reaction rate depends on the catalyst used (CAU-17 > CAU-7 > 4). This suggests that CAU-17 is a superior catalyst for this reaction compared with 4 and CAU-7. The differences in activity between CAU-7 and 4 can be explained in terms of stability. PXRD of the different catalysts after the activation and after the reaction (Fig. S31-S32) revealed that the catalyst $\mathbf{4}$ structurally degrades during the activation.
The catalytic activity of $\mathrm{CAU}-17$ in the regioselective ring opening reaction of styrene oxide is inferior to those reported for other MOFs $^{[42,44,55]}$ but there are also studies that reports the necessity of long reaction times. ${ }^{[56,57]}$ Nevertheless the study clearly demonstrates the existence of coordinatively unsaturated sites in the crystal structure of CAU-17.

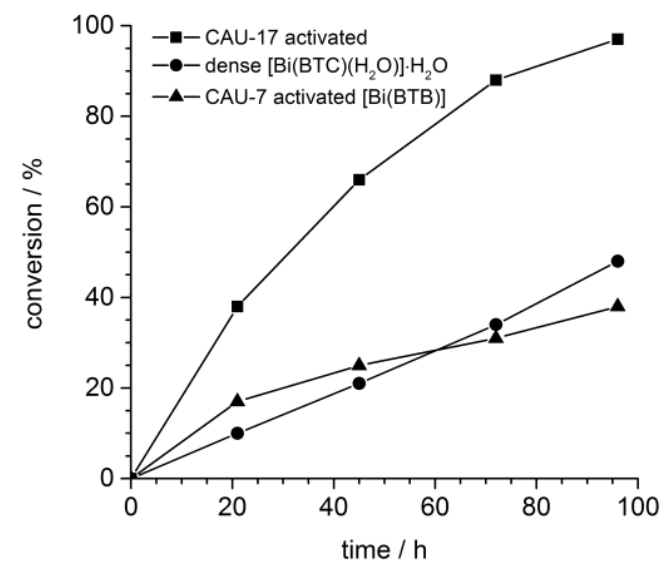

Figure 8. Time conversion plot for the ring opening of styrene oxide by CAU-17, dense phase 4 and $\mathrm{CAU}-7$ as catalysts. These catalysts were activated before catalytic reaction at $120^{\circ} \mathrm{C}$ for $3 \mathrm{~h}$ under vacuum.

\section{Conclusions}

In summary, a detailed analysis of the synthesis of CAU-17 was presented displaying not only its fast formation but also its transformation into a dense phase upon prolonged reaction times as well as the formation of another bismuth trimesate $\left.\mathrm{Bi}(\mathrm{HBTC})\left(\mathrm{NO}_{3}\right)(\mathrm{MeOH})\right] \cdot \mathrm{MeOH}(3)$ upon increase of the reactant concentrations. The in situ PXRD results exemplify the possible importance of short reaction times in MOF synthesis. The reaction of bismuth nitrate and trimesic acid depends strongly on the solvent employed. As observed for water as solvent multiple crystalline phases are also obtained in methanol. The crystal structure exhibits some interesting features. Thus the thermal stability $\left(\sim 350{ }^{\circ} \mathrm{C}\right)$ and the possibility to remove coordinating water molecules render this compound as a heterogeneous catalyst in the $100 \%$ regioselective conversion of styrene oxide into 2-methoxy-2-phenylethanol. The size of the hexagonal onedimensional pores allows for a high adsorption capacity and selectively for greenhouse gases such as $\mathrm{CO}_{2}$ and $\mathrm{SF}_{6}$ over $\mathrm{N}_{2}$. Last not least the temperature-dependent PXRD study of CAU-17 has revealed interesting structural behavior, which needs to be explained in detail in the future.

\section{Experimental Section}

The chemicals were purchased from Aldrich, Alfa Aesar or Walter CMP and used without further purification. HPLC grade methanol was used as 
the solvent in catalytic reactions. Syntheses were carried out under solvothermal conditions in a Biotage Initiator microwave oven employing 10 or $30 \mathrm{~mL}$ vials or in a custom-made aluminum block placed on a heating stirrer plate using DURAN culture tubes $12 \times 100 \mathrm{~mm}$ D50 GL 14M.KAP. PXRD measurements were carried out with $\mathrm{CuK}_{\alpha 1}$ and MoK $\mathrm{K}_{\alpha 1}$ radiation on a Stoe Stadi P Combi diffractometer in transmission geometry, equipped with a MYTHEN detector. Temperature-dependent PXRD was performed in a Stoe capillary furnace in a $0.5 \mathrm{~mm}$ quartz capillary. Gas Chromatography $6890 \mathrm{~N}$ network Agilent Technologies was used for determining the conversion and selectivity using a FID detector and the product was confirmed by Hewlett Packard 5971A GC-MS instrument in catalytic reactions. The sequential LeBail-fit was performed in TOPAS Academic 4. ${ }^{[58]}$ Thermogravimetric measurements were performed on a NETZSCH STA-409CD under air flow of $75 \mathrm{ml} / \mathrm{min}$ with a heating rate of 4 $\mathrm{K} /$ min. IR spectra were measured on a Bruker ALPHA-P spectrometer using an ATR unit.

In situ PXRD crystallization experiment: The in situ PXRD crystallization experiments were carried out at PETRA III, beamline P09 at DESY, Hamburg (Germany). Diffraction data were collected on a Perkin Elmer Digital X-ray Flat Panel Detector $(\lambda=0.53905 \AA)$. The sample-detector distance was set to $592 \mathrm{~mm}$ to measure a $2 \theta$-range of approximately 0.7 $36^{\circ}$. The custom-made SynRAC set-up was used to heat the reaction mixture. ${ }^{[52]}$ The reaction mixture was cooled after the reaction with compressed air. Detailed full temperature profiles of the reactions are provided in the SI (Fig. S4, S7, S9). The data was normalized to the Alreflection of the reactor window in order to eliminate absorption problems, caused by particles in the beam, which lead to fluctuating intensity.

Preparation of the in situ PXRD experiment $\mathrm{Bi}\left(\mathrm{NO}_{3}\right)_{3} /$ trimesic acid/MeOH: A mixture of trimesic acid $\left(\mathrm{H}_{3} \mathrm{BTC}, 50.0 \mathrm{mg}, 238 \mu \mathrm{mol}\right)$ and ground $\mathrm{Bi}\left(\mathrm{NO}_{3}\right)_{3} .5 \mathrm{H}_{2} \mathrm{O}(100 \mathrm{mg}, 207 \mu \mathrm{mol})$ in $2.5 \mathrm{~mL} \mathrm{MeOH}$ was dissolved at room temperature by shaking for $1 \mathrm{~min}$, waiting $1 \mathrm{~min}$ and shaking for $1 \mathrm{~min}$ again. The sealed glass vial was heated in a custommade reactor system to $120-140{ }^{\circ} \mathrm{C}$ under stirring.

Synthesis of $\left[\mathrm{Bi}(\mathrm{BTC})\left(\mathrm{H}_{2} \mathrm{O}\right)\right]$ (CAU-17, 1): To a mixture of trimesic acid $\left(\mathrm{H}_{3} \mathrm{BTC}, 250 \mathrm{mg}, 1.19 \mathrm{mmol}\right)$ and ground $\mathrm{Bi}\left(\mathrm{NO}_{3}\right)_{3} \cdot 5 \mathrm{H}_{2} \mathrm{O}(502 \mathrm{mg}$, $1.04 \mathrm{mmol}$ ) in a $30 \mathrm{~mL}$ glass vial, $20 \mathrm{~mL} \mathrm{MeOH}$ were added carefully. The sealed vial was heated in the microwave oven to $120^{\circ} \mathrm{C}$ and kept at this temperature for $20 \mathrm{~min}$ under stirring with $600 \mathrm{rpm}$. After cooling the solid product was filtered off and washed with $\mathrm{MeOH}$. A white powder was obtained in a yield of $239.5 \mathrm{mg}\left(46 \%\right.$ based on $\left.\mathrm{H}_{3} \mathrm{BTC}\right)$. Phase purity was confirmed by PXRD (Fig. S29-S30) and elemental analysis (calculated (\%) for $\mathrm{Bi}\left(\mathrm{C}_{9} \mathrm{O}_{6} \mathrm{H}_{3}\right)\left(\mathrm{H}_{2} \mathrm{O}\right)_{4}$ : $\mathrm{C} 22.1 \mathrm{H} 2.27$; measured (\%): $\mathrm{C} 21.7 \mathrm{H} \mathrm{1.49)}$.

Synthesis of the final product of the in situ experiments $\left(\mathrm{Bi}_{2} \mathrm{O}(\mathrm{OH})_{3}\left(\mathrm{NO}_{3}\right) \cdot \mathbf{x H}_{2} \mathrm{O}, 2\right)$ : To obtain a suitable amount of $\mathbf{2}$ for characterization, the following procedure was used: $\mathrm{A}$ mixture of trimesic acid $\left(\mathrm{H}_{3} \mathrm{BTC}, 250 \mathrm{mg}, 1.19 \mathrm{mmol}\right)$ and ground $\mathrm{Bi}\left(\mathrm{NO}_{3}\right)_{3} .5 \mathrm{H}_{2} \mathrm{O}(502 \mathrm{mg}$, $1.04 \mathrm{mmol}$ ) was dissolved in $20 \mathrm{~mL} \mathrm{MeOH}$ at room temperature by shaking for $1 \mathrm{~min}$, waiting $1 \mathrm{~min}$ and shaking for $1 \mathrm{~min}$ again in a $30 \mathrm{~mL}$ glass vial. The sealed vial was heated in the microwave oven to $120^{\circ} \mathrm{C}$ and kept at this temperature for $3 \mathrm{~h}$ under stirring with $600 \mathrm{rpm}$. After cooling the solid product was filtered off and washed with $\mathrm{MeOH}$. A white powder was obtained in a yield of $240 \mathrm{mg}$. Further details are given in the SI.

Synthesis of $\left[\mathrm{Bi}(\mathrm{HBTC})\left(\mathrm{NO}_{3}\right)(\mathrm{MeOH})\right] \cdot \mathrm{MeOH}$ (3): To a mixture of trimesic acid $\left(\mathrm{H}_{3} \mathrm{BTC}, 300 \mathrm{mg}, 1.43 \mathrm{mmol}\right)$ and ground $\mathrm{Bi}\left(\mathrm{NO}_{3}\right)_{3} .5 \mathrm{H}_{2} \mathrm{O}$ (603 mg, $1.24 \mathrm{mmol}$ ), $2 \mathrm{~mL} \mathrm{MeOH}$ were added. The sealed glass vial (DURAN culture tubes $12 \times 100 \mathrm{~mm}$ D50 GL 14M.KAP) was placed in a preheated aluminium block for $50 \mathrm{~min}$ at $50^{\circ} \mathrm{C}$ without stirring. The solid product was filtrated and washed with $10 \mathrm{~mL} \mathrm{MeOH}$. A white powder was obtained by centrifugation in a yield of $438 \mathrm{mg}$ ( $69 \%$ based on $\left.\mathrm{H}_{3} \mathrm{BTC}\right)$.
Phase purity was confirmed by PXRD (Fig. S36) and elemental analysis (calculated (\%) for $\mathrm{Bi}\left(\mathrm{C}_{9} \mathrm{O}_{6} \mathrm{H}_{4}\right)\left(\mathrm{NO}_{3}\right)\left(\mathrm{CH}_{3} \mathrm{OH}\right)\left(\mathrm{H}_{2} \mathrm{O}\right)$ : C $22.7 \mathrm{H} 1.90 \mathrm{~N} 2.65$; measured (\%): $\mathrm{C} 21.7 \mathrm{H} 1.61 \mathrm{~N} 2.92$ ). The sample was stored at $4{ }^{\circ} \mathrm{C}$ to avoid evaporation of the $\mathrm{MeOH}$, which leads to degradation of the structure. Suitable single crystals could be obtained by mixing trimesic acid $\left(\mathrm{H}_{3} \mathrm{BTC}\right.$, $125 \mathrm{mg}, 595 \mu \mathrm{mol})$ and ground $\mathrm{Bi}\left(\mathrm{NO}_{3}\right)_{3} \cdot 5 \mathrm{H}_{2} \mathrm{O}(251 \mathrm{mg}, 517 \mu \mathrm{mol})$ with $5 \mathrm{~mL} \mathrm{MeOH}$ at room temperature by shaking. The sealed glass vial was heated in the microwave oven to $120^{\circ} \mathrm{C}$ and kept at this temperature for 18 min without stirring. The obtained white single crystals were collected by filtration and washed with $\mathrm{MeOH}$.

Synthesis of CAU-7: Synthesis was performed following a previously described procedure. ${ }^{[20]}$

Synthesis of $\left[\mathrm{Bi}(\mathrm{BTC})\left(\mathrm{H}_{2} \mathrm{O}\right)\right] \cdot \mathrm{H}_{2} \mathrm{O}(4$, dense phase): The synthesis has been derived from the literature known synthesis. ${ }^{[28]}$ To a mixture of trimesic acid $\left(\mathrm{H}_{3} \mathrm{BTC}, 300 \mathrm{mg}, 1.43 \mathrm{mmol}\right)$ and ground $\mathrm{Bi}\left(\mathrm{NO}_{3}\right)_{3} .5 \mathrm{H}_{2} \mathrm{O}$ (693 mg, $1.43 \mathrm{mmol}$ ), $20 \mathrm{~mL}$ distilled water were added. The sealed glass vial was heated in the microwave oven to $130^{\circ} \mathrm{C}$ and kept at this temperature for $5 \mathrm{~min}$ under stirring with $600 \mathrm{rpm}$. After cooling the product was filtered off and washed with DMF and water. A white powder was obtained in a yield of $636.6 \mathrm{mg}$ ( $99 \%$ based on $\left.\mathrm{H}_{3} \mathrm{BTC}\right)$. Phase purity was confirmed by PXRD (Fig. S32) and elemental analysis (calculated (\%) for $\mathrm{Bi}\left(\mathrm{C}_{9} \mathrm{O}_{6} \mathrm{H}_{3}\right)\left(\mathrm{H}_{2} \mathrm{O}\right)_{2}$ : C $23.9 \mathrm{H}$ 1.56; measured (\%): $\left.\mathrm{C} 22.9 \mathrm{H} 1.96\right)$.

Chemical stability experiments: The chemical stability was investigated by using the following procedure: A defined amount of $2 \mathrm{~mL}(4 \mathrm{~mL}$ in case of solutions at different $\mathrm{pH}$ ) were added to $20 \mathrm{mg}$ of 1 in a $5 \mathrm{~mL}$ glass vial with a stir bar. The mixture was stirred for $24 \mathrm{~h}$ at room temperature and then filtered off and washed with $2 \mathrm{~mL}$ of methanol. The water stability experiment was carried out similar to the in situ experiments. For this, 15 $\mathrm{mg}$ of 1 was stirred in $2.5 \mathrm{ml} \mathrm{H}_{2} \mathrm{O}$ while recording PXRD patterns of the mixture and subsequently elevating the temperature (compare: In situ PXRD crystallization experiment).

Gas adsorption experiments: Prior to the gas adsorption measurements, the samples were first pretreated under dynamic vacuum at $120^{\circ} \mathrm{C}$ for 6 hours, then at $300^{\circ} \mathrm{C}$ for further 6 hours. The pretreatment steps were carried out using a Micromeritics SmartVacPrep sample preparation device. Gas adsorption measurements were carried out using a Micromeritics ASAP2020 analyzer. Specific surface area (BET and Langmuir), DFT pore size distribution and total pore volume were calculated using the nitrogen sorption isotherm recorded at liquid nitrogen temperature $\left(-196{ }^{\circ} \mathrm{C}\right)$ for $\mathrm{p} / \mathrm{p}_{0}=0$ to $0.99 . \mathrm{N}_{2}, \mathrm{SF}_{6}$ and $\mathrm{CO}_{2}$ adsorption isotherms were recorded at $0-55^{\circ} \mathrm{C}$ for a pressure range between 0 and 1 bar. A water adsorption isotherm was recorded on the same instrument using the vapor sorption module at $20^{\circ} \mathrm{C}$ for $0 \leq p / p_{0} \leq 0.95$. Adsorption equilibrium was defined as when the pressure change of the system drops below $0.01 \%$ during a $10 \mathrm{~s}$ interval (with a minimum $100 \mathrm{~s}$ delay). The selectivity calculations were carried out using MATLAB R2014a running with a set of self-written codes.

Procedure for catalytic reactions: A $25 \mathrm{~mL}$ round-bottomed flask was charged with the catalyst and styrene oxide $(1 \mathrm{mmol})$ in methanol $(3 \mathrm{~mL})$. The ratio between styrene oxide to $\mathrm{Bi}$ in the activated CAU-17 was about 10:1. The reaction mixture was stirred for the required time. The reaction was monitored periodically by analyzing the sample by GC until the completion of reaction. The percentage conversion and selectivity was determined by GC analysis. The product was confirmed by GC-MS analysis. Whenever required, the catalyst was activated at $120^{\circ} \mathrm{C}$ for $3 \mathrm{~h}$ under vacuum. 
Crystal structure determination of $\left[\mathrm{Bi}(\mathrm{HBTC})\left(\mathrm{NO}_{3}\right)(\mathrm{MeOH})\right] \cdot \mathrm{MeOH}(3)$ : Single crystal X-ray diffraction data were collected on a Bruker D8 Venture at $150 \mathrm{~K}(\lambda=0.71073 \AA)$. Data reduction was performed with SAINT and absorption corrections were applied using the multi-scan method (SADABS). Structure determination was performed in ShelXS. ${ }^{[59]}$ Atoms were refined using a full-matrix least squares technique on $\mathrm{F}^{2}$ in ShelXL. All non-hydrogen atoms were refined with anisotropic displacement parameters. A riding model was used to constrain the coordinates of hydrogen atoms bonded to parent carbon atoms. Distant restraints were applied to $\mathrm{O}-\mathrm{H}$ bonds in $\mathrm{COOH}$ in trimesate ligands and $\mathrm{OH}$ groups of methanol.

\section{Acknowledgements}

We thank Niclas Heidenreich and Jörg Strempfer for their help during the collection of the in situ PXRD data and also Helge Reinsch and Dirk Lenzen for helpful discussions. This work has been supported by the MATsynCELL project through the Röntgen-Ångström Cluster, supported by the Swedish Research Council (VR) and the German Federal Ministry of Education and Research (BMBF). Lukas Lundgren of Uppsala University is acknowledged for his valuable contributions towards the IAST calculations. ADM thanks University Grants Commission, New Delhi for the award of Assistant Professorship under its Faculty Recharge Programme and also thanks Department of Science and Technology, India for the financial support through Extra Mural Research Grant (EMR/2016/006500). ADM thanks DFG for the financial support towards three months research stay at University of Kiel, Germany under INSA-DFG bilateral exchange program. AKI is additionally supported by a scholarship from the Knut and Alice Wallenberg Foundation (KAW) and the Swedish Foundation for Strategic Research (SSF).

Keywords: bismuth $\cdot$ metal-organic framework $\cdot$ porous material - in situ $\cdot \mathrm{PXRD} \cdot \mathrm{SF}_{6}$ sorption $\cdot$ styrene oxide $\bullet$ heterogeneous catalysis

[1] N. R. Catarineu, A. Schoedel, P. Urban, M. B. Morla, C. A. Trickett, O. M. Yaghi, J. Am. Chem. Soc. 2016, 138, 10826-10829.

[2] G. Férey, C. Mellot-Draznieks, C. Serre, F. Millange, J. Dutour, S. Surblé, I. Margiolaki, Science 2005, 309, 2040-2042.

[3] P. Horcajada, T. Chalati, C. Serre, B. Gillet, C. Sebrie, T. Baati, J. F. Eubank, D. Heurtaux, P. Clayette, C. Kreuz, J.-S. Chang, Y. K. Hwang V. Marsaud, P.-N. Bories, L. Cynober, S. Gil, G. Férey, P. Couvreur, R. Gref, Nature materials 2010, 9, 172-178.

[4] R. Kitaura, K. Seki, G. Akiyama, S. Kitagawa, Angew. Chem, Int. Ed. 2003, 42, 428-431.

[5] K. Kongpatpanich, S. Horike, M. Sugimoto, T. Fukushima, D. Umeyama, Y. Tsutsumi, S. Kitagawa, Inorg. Chem. 2014, 53, 9870-9875.

[6] J. L.C. Rowsell, O. M. Yaghi, Microporous Mesoporous Mater. 2004, 73, 3-14.

[7] K. Sumida, D. L. Rogow, J. A. Mason, T. M. McDonald, E. D. Bloch, Z. R. Herm, T.-H. Bae, J. R. Long, Chem. Rev. 2012, 112, 724-781.

[8] E. Barea, C. Montoro, J. A. R. Navarro, Chem. Soc. Rev. 2014, 43, 54195430.

[9] A. Dhakshinamoorthy, H. Garcia, Chem. Soc. Rev. 2014, 43, 5750-5765.
[10] P. Horcajada, R. Gref, T. Baati, P. K. Allan, G. Maurin, P. Couvreur, G. Ferey, R. E. Morris, C. Serre, Chem. Rev. 2012, 112, 1232-1268.

[11] P. de Marcillac, N. Coron, G. Dambier, J. Leblanc, J.-P. Moalic, Nature 2003, 422, 876-878.

[12] Y. Yang, R. Ouyang, L. Xu, N. Guo, W. Li, K. Feng, L. Ouyang, Z. Yang, S. Zhou, Y. Miao, J. Coord. Chem. 2014, 68, 379-397.

[13] V. André, A. Hardeman, I. Halasz, R. S. Stein, G. J. Jackson, D. G. Reid, M. J. Duer, C. Curfs, M. T. Duarte, T. Friščić, Angew. Chem, Int. Ed. 2011, 50, 7858-7861.

[14] P. C. Andrews, G. B. Deacon, C. M. Forsyth, P. C. Junk, I. Kumar, M. Maguire, Angew. Chem, Int. Ed. 2006, 45, 5638-5642.

[15] W. Li, L. Jin, N. Zhu, X. Hou, F. Deng, H. Sun, J. Am. Chem. Soc. 2003 125, 12408-12409.

[16] Y. Wang, S. Takki, O. Cheung, H. Xu, W. Wan, L. Öhrström, A. K. Inge Chem. Commun. 2017, 53, 7018-7021.

[17] O. K. Farha, J. T. Hupp, Acc. Chem. Res. 2010, 43, 1166-1175.

[18] M. W. Stoltzfus, P. M. Woodward, R. Seshadri, J.-H. Klepeis, B. Bursten, Inorg. Chem. 2007, 46, 3839-3850.

[19] M. Weber, M. Schlesinger, M. Walther, D. Zahn, C. A. Schalley, M Mehring, Z. Kristallogr. - Cryst. Mater. 2017, 232, 1.

[20] M. Feyand, E. Mugnaioli, F. Vermoortele, B. Bueken, J. M. Dieterich, T. Reimer, U. Kolb, D. de Vos, N. Stock, Angew. Chem. Int. Ed. 2012, 124 , 10373-10376.

[21] M. Savage, S. Yang, M. Suyetin, E. Bichoutskaia, W. Lewis, A. J. Blake, S. A. Barnett, M. Schröder, Chem. - Eur. J. 2014, 20, 8024-8029.

[22] A. K. Inge, M. Köppen, J. Su, M. Feyand, H. Xu, X. Zou, M. O'Keeffe, N. Stock, J. Am. Chem. Soc. 2016, 138, 1970-1976.

[23] M. Köppen, O. Beyer, S. Wuttke, U. Lüning, N. Stock, Dalton Trans. 2017, 46, 8658-8663.

[24] R. I. Walton, F. Millange in The Chemistry of Metal-Organic Frameworks, Wiley-VCH Verlag GmbH \& Co. KGaA, 2016, pp. 729-764

[25] N. Pienack, W. Bensch, Angew. Chem, Int. Ed. 2011, 50, 2014-2034.

[26] T. Rhauderwiek, N. Heidenreich, H. Reinsch, S. Øien-Ødegaard, K. A Lomachenko, U. Rütt, A. V. Soldatov, K. P. Lillerud, N. Stock, Cryst. Growth Des. 2017, 17, 3462-3474.

[27] M. Wendt, L. K. Mahnke, N. Heidenreich, W. Bensch, Eur. J. Inorg. Chem. 2016, 2016, 5393-5398.

[28] M. Feyand, M. Köppen, G. Friedrichs, N. Stock, Chem. - Eur. J. 2013, 19, 12537-12546.

[29] G. Wang, Y. Liu, B. Huang, X. Qin, X. Zhang, Y. Dai, Dalton Trans. 2015, 44, 16238-16241.

[30] H. Pasdar, M. Namegh, H. Aghabozorg, B. Notash, Acta Crystallogr, Sect. E: Struct. Rep. Online 2011, 67, m353-m354.

[31] A. H. Chughtai, N. Ahmad, H. A. Younus, A. Laypkov, F. Verpoort, Chem. Soc. Rev. 2015, 44, 6804-6849.

[32] A. Corma, H. García, F. X. Llabrés i Xamena, Chem. Rev. 2010, 110, 4606-4655.

[33] A. Dhakshinamoorthy, M. Opanasenko, J. Čejka, H. Garcia, Catal. Sci. Technol. 2013, 3, 2509.

[34] O. A. Kholdeeva, Catal. Today 2016, 278, 22-29.

[35] Y.-X. Zhou, Y.-Z. Chen, Y. Hu, G. Huang, S.-H. Yu, H.-L. Jiang, Chem. Eur. J. 2014, 20, 14976-14980.

[36] A. Herbst, A. Khutia, C. Janiak, Inorg. Chem. 2014, 53, 7319-7333.

[37] A. Santiago-Portillo, J. F. Blandez, S. Navalón, M. Álvaro, H. García, Catal. Sci. Technol. 2017, 7, 1351-1362.

[38] F. Vermoortele, M. Vandichel, B. van de Voorde, R. Ameloot, M Waroquier, V. van Speybroeck, D. E. de Vos, Angew. Chem, Int. Ed. 2012, 51, 4887-4890.

[39] B. Li, K. Leng, Y. Zhang, J. J. Dynes, J. Wang, Y. Hu, D. Ma, Z. Shi, L. Zhu, D. Zhang, Y. Sun, M. Chrzanowski, S. Ma, J. Am. Chem. Soc. 2015 137, 4243-4248.

[40] M. H. Beyzavi, R. C. Klet, S. Tussupbayev, J. Borycz, N. A. Vermeulen, C. J. Cramer, J. F. Stoddart, J. T. Hupp, O. K. Farha, J. Am. Chem. Soc. 2014, 136, 15861-15864. 
[41] M. H. Beyzavi, N. A. Vermeulen, A. J. Howarth, S. Tussupbayev, A. B. League, N. M. Schweitzer, J. R. Gallagher, A. E. Platero-Prats, N. Hafezi, A. A. Sarjeant, J. T. Miller, K. W. Chapman, J. F. Stoddart, C. J. Cramer, J. T. Hupp, O. K. Farha, J. Am. Chem. Soc. 2015, 137, 13624-13631.

[42] A. Dhakshinamoorthy, M. Alvaro, H. Garcia, Chem. - Eur. J. 2010, 16, 8530-8536.

[43] K. Hindelang, S. I. Vagin, C. Anger, B. Rieger, Chem. Commun. 2012 , 48, 2888-2890.

[44] D. Jiang, A. Urakawa, M. Yulikov, T. Mallat, G. Jeschke, A. Baiker, Chem - Eur. J. 2009, 15, 12255-12262.

[45] Y. Liu, R. C. Klet, J. T. Hupp, O. Farha, Chem. Commun. 2016, 52, 78067809.

[46] N. E. Thornburg, Y. Liu, P. Li, J. T. Hupp, O. K. Farha, J. M. Notestein, Catal. Sci. Technol. 2016, 6, 6480-6484.

[47] B. Zhou, W. Li, J. Zhang, J. Phys. Chem. C 2017.

[48] S. Solomon, D. Qin, M. Manning, Z. Chen, M. Marquis, K.B. Averyt, M. Tignor, H.L. Miller, Contribution of Working Group I to the Fourth Assessment Report of the Intergovernmental Panel on Climate Change: Technical Summary, Cambridge, United Kingdom and New York, NY, USA, 2007.

[49] M. Toyoda, H. Murase, T. Imai, H. Naotsuka, A. Kobayashi, K. Takano, K. Ohkuma, IEEE Trans. Power Delivery 2003, 18, 442-448.

[50] M.-B. Kim, S.-J. Lee, C. Y. Lee, Y.-S. Bae, Microporous Mesoporous Mater. 2014, 190, 356-361.

[51] T. Hasell, M. Miklitz, A. Stephenson, M. A. Little, S. Y. Chong, R. Clowes, L. Chen, D. Holden, G. A. Tribello, K. E. Jelfs, A. I. Cooper, J. Am. Chem Soc. 2016, 138, 1653-1659.

[52] N. Heidenreich, U. Rütt, M. Köppen, A. K. Inge, S. Beier, A.-C. Dippel, R. Suren, N. Stock, Rev. Sci. Instrum. 2017, 88, 104102.

[53] M. Gemmi, M. G. I. La Placa, A. S. Galanis, E. F. Rauch, S. Nicolopoulos, J. Appl. Crystallogr. 2015, 48, 718-727.

[54] D. Dubbeldam, K. S. Walton, D. E. Ellis, R. Q. Snurr, Angew. Chem, Int. Ed. 2007, 46, 4496-4499.

[55] D. Jiang, T. Mallat, F. Krumeich, A. Baiker, Journal of Catalysis 2008 257, 390-395.

[56] G. Kumar, A. P. Singh, R. Gupta, Eur. J. Inorg. Chem. 2010, 2010, 51035112.

[57] P. Silva, D. Ananias, S. M. Bruno, A. A. Valente, L. D. Carlos, J. Rocha, F. A. Almeida Paz, Eur. J. Inorg. Chem. 2013, 2013, 5576-5591.

[58] A. Coelho, TOPAS Academic 4.1; Coelho Software, 2007.

[59] G. M. Sheldrick, Acta Crystallogr, Sect. A: Found. Crystallogr. 2008, 64, 112-122. 


\section{Entry for the Table of Contents}

\section{FULL PAPER}

The metal-organic framework CAU17 is the first bismuth MOF synthesized from cheap starting materials. Its properties were investigated with in situ PXRD (fast crystallization), thermodiffraction (shrinking unit cell upon heating), $\mathrm{N}_{2} / \mathrm{CO}_{2} / \mathrm{SF}_{6}$ sorption (high selectivity) and by using CAU-17 as catalyst in the ring opening reaction of styrene oxide.

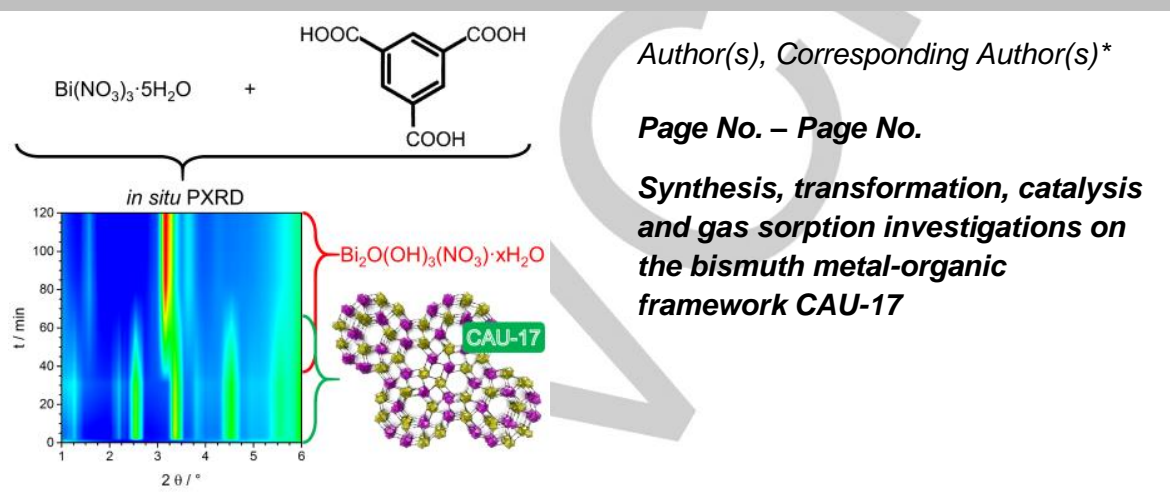

Page No. - Page No.

Synthesis, transformation, catalysis he bismuth metal-organic ramework CAU-17 